\title{
Analysis of Chemical Warfare Agents in Water Using Single-Drop Microextraction
}

\author{
Yang-Gi Park, Sung Ki Kim, Kibwan Choi, ${ }^{\dagger}$ Byung-Hoon Son, Ju-Sub Park, and Hong-Ku Kang ${ }^{\dagger}$ \\ Department of Chemistry and Environmental Analysis, Chemical Defense Research Institute. Seoul 137-180, Korea \\ E-mail: hongkttkangatempal.com \\ Department of Chemistrv. Seoul Rational Lniversity Seoul 151-747, Korea \\ Received April 6, 2008, Accepted October 7, 2008
}

\begin{abstract}
Single-drop microextraction (SDME) is an extraction methodology where the drop plays an essential role as extracts. It was evaluated for the GC-MS deternination of nerve agents, one class of the chemical warfare agents (CWAs). Since these nerve agents are highly toxic, it is important to detect the nerve agents in the environmental samples. Several affecting factors including extraction solvents, stirring rate, extraction time, and amounts of salt were optimized. The limit of detections (LODs) were $0.1-10 \mathrm{ng} / \mathrm{mL}$ and the relative standard deviations (RSDs $\%$, $\mathrm{n}=5$ ) were in the range of $6.3 \%$ to $9.0 \%$ for four nerve agents. Without pretreatment of the environmental samples, 5-103 fold enrichments and 48-100\% recovery were accomplished. These results demonstrated the feasibility of this method for on-site and off-site analy sis of water sample collected from suspicious CWAs site.
\end{abstract}

Key Words: Single-drop microextraction. Chemical warfare agents. Nerve agents

\section{Introduction}

The Organization for Prohibition of Chemical Weapons (OPCW) inspects relevant industrial or military sites to implement Chemical Weapons Convention (CWC) which bans the development. production. stockpiling. and transferring of these dreadful weapons in various countries. This inspection includes various verification activities (on-site analysis by OPCW inspectors in alleged point and off-site analysis designated by OPCW laboratories). A key point of verification activities is to analyze chemical warfare agents (CWAs) regardless of sample types. Therefore. a pre-treatment of CWAs from the complex environmental samples is very important for analyzing its trace. The pre-treatment techniques for analyzing CWAs include liquid-liquid extraction. ${ }^{2}$ solid-phase extraction ${ }^{3}$ and solid-phase microextraction. ${ }^{-1}$ These extraction techniques were adopted when preparing samples of different sample matrices. Each extraction technique has their strengths and weaknesses and can be used according to the properties of sample and matrix

Recently a fast, simple, inexpensive and solvent free sample preparation technique has been used for extracting CWAs from water. This technique. so called liquid-phase microextraction (LPME) can be performed as a pre-treatment which makes extraction and pre-concentration occur simultaneously. This technique involves hollow fiber protected liquid-phase microestraction ${ }^{5,6}$ and single-drop microextraction. ${ }^{7,8}$ In case of hollow fiber liquid-phase microextraction, a hollow fiber containing organic solvent is attached into the tip of the syringe needle. and the analytes of interesting are extracted into the organic solvent through a thin layer of a hollow fiber and then detected by GC or GC-MS. typically: After the organic solvent is retracted into the syringe, the hollow fiber is discarded. Therefore. a carry-over effect can be removed. The extraction of CWAs and convention related compounds (CRCs) has been carried out using this technique. " The CWAs were directly extracted into organic solvent through hollow fiber and the $\mathrm{CRCs}$ having low volatility were extracted and de- rivatized before GC-MS analy sis. ${ }^{10}$

Single-drop microextraction (SDME) was also developed as a solvent minimized sample preparation method. and since small amount of solvent is used. exposure to toxic organic phase can be ninimized. ${ }^{11}$ A drop of the solvent suspended at the tip of syringe needle is exposed to an aqueous phase. After extraction for a prescribed time. the droplet is retracted into the syringe and is injected into the GC or GC-MS for analysis. Since SDME is simpler and faster than other liquid extraction tecluniques, this nicroextraction has been very frequently applied to various studies. ${ }^{13.15}$

In the present report, SDME is applied to the extraction of CWAs from water sample. The chemicals chosen for this study were five highly toxic nerve agents, tabun (GA), sarin (GB), soman (GD). and GF. The objectives of the present study are to investigate the effect of several parameters using this extraction method and to study the applicability of SDME to determine nerve agents in water sample.

\section{Experimental}

Reagents and Chemicals. The conpounds selected for extraction were four nerve agents (>98\%): ethyl $X, \hat{\text {-dimethyl- }}$ phosphoramidocyanidate (GA). isopropyl methylphosphonofluoridate (GB), pinacolyl methylphosphonofluoridate (GD). and cyclohexyl methylphosphonofluoridate (GF). The nerve agents were all synthesized at CDRI, the Chemical Defense Research Institute (Seoul, Korea). Figure I shows the stnuctures of the nerve agents tested. Organic solvents such as toluene. trichloroethylene. carbon tetrachloride. octane and acetonitrile were purchased from Sigma (St. Louse, MO, USA). Decane as internal standard was also purchased from Sigma. Sodium clloride $(\mathrm{NaCl})$ was obtained from Merk (Darmstadt, Germany). Deionized water was prepared from a NANO pure II purification system (Bamstead. Dubuque. IA. USA) for spiking the aqueous santples. The stock solutions were prepared in acetonitrile with concentration levels of $2000 \mu \mathrm{g} / \mathrm{L}$ for each agent and all of working solutions were prepared at 
<smiles>CCOP(N)(=O)N(C)C</smiles>

GA<smiles>CC(C)OP(C)(=O)P</smiles>

GB<smiles>CC(OP(C)(C)=O)C(C)(C)C</smiles>

GD<smiles>CP(=O)(F)OC1CCCC1</smiles>

GF
Figure 1. The structure of nerve agents.

$10 \mu \mathrm{g}$ L concentration by diluting appropriate volume of stock solution with deionized water daily.

The sea water sample was obtained from the sea in front of the Inchen, Korea and the river water sample from the lian River, Seoul, Korea. Finally, field water was collected from Mt. In-rueng. Seoul, Korea. All water samples were collected in polystyrene bottles and filtered through a $0.45 \mathrm{tm}$ microfilters (Millipore, MA, USA).

Safety Considerations. The CWAs are very toxic chemicals. The synthesis and storage should be donc in an efficient fume hood with intensified ventilation. Protective mask, glove, and suit should be won when the agents are handled. A $10 \%$ sodium lydroxide solution or other decontaminants should be always prepared and used for decontamination of nerve agents.

GC-MS Analysis. The GC/MS analysis was performed using an Agilent $6890 \mathrm{GC}$ equipped with a mass selective detector ( $A$ gilent Technologies, San,Jose, CA, USA). Analysis was conducted with a HP-5MS column $(30 \mathrm{~m}, 0.25 \mathrm{~mm}, 0.25$ fam) purchased from J\&W Scientific (Folsom, CA, USA). I ielium was used as carrier gas and set at $0.7 \mathrm{~mL} / \mathrm{min}$. The temperature program used for the analysis was: from $50^{\circ} \mathrm{C}$ ( 1 min) $10250^{\circ} \mathrm{C}(2 \mathrm{lmin})$ at $10^{\prime \prime} \mathrm{C} / \mathrm{min}$. The injector was set to $250^{\circ} \mathrm{C}$ with a splitless mode. The .MS system was operated in the clectron ionization (EI) mode, and for determination of nerve agents, selected ion monitoring (SIM) mode was performed. A mass scan from $m \geq 50$ to 500 was used, and the ions selected for (GC-SIM analysis were $m=70$ and 133 for GA, $m=99$ and 125 for GB, $m=99$ and 126 for Gl), $m=99$ and 137 for $\mathrm{GF}$, and $m z 85$ and 124 for decane, acting as an intemal standard.

Extraction Procedure. $\triangle$ 3-mL volume of aqueous sample was placed in a 4-mL extraction vial containing a PTFF-coated magnetic stirring bar $(7 \mathrm{~mm} / 2 \mathrm{~mm})$ and the extraction vial was maintained at $25^{\circ} \mathrm{C}$ with a circulating water bath. A model $\# 701,10-\mu t$. syringe with a $22^{\circ}$ bevel needle tip (Hamilton, $N V$, U.S.A was used. Before extraction, the syringe was rinsed with extracting solvent 10 times to avoid bubble formation and contamination. $\Lambda 1.5, t \mathrm{~L}$ of the appropriatc organic solvent was drawn into the syringe for the extraction and a 0.5 fll of organic solvent was expelled to remove the air bubbles. After the needle passed through the septum, the needle tip was kept below the surface of the solution and the plunger was depressed until the $1.0 \mu \mathrm{L}$ droplet of the organic phase was exposed to the sample. Magnetic stirring at $100-800 \mathrm{rpm}$ was applicd for $10-40$ min during the extraction. After cxtraction. the plunger was withdrawn and the drop was retracted carefully into the syringe. The syringe was then transferred to the heated injector of GC/MS system and analysis was carried out. The analytical signal was taken as the area ratio of the analyte peak to the internal standard peak.

\section{Results and Discussion}

A SDME is a process of the partition of analyte between the water sample and the extracts. To cnhance the extraction efficiency, several parameters such as selection of solvent, stirring rate, extraction time, and addition of salt were investigated. To obtain optimized conditions, the ratio of the peak area of analyte to the peak area of internal standards were used in GC/MS analysis.

Organic Solvent. Partitioning of the analytes between the sample and the extracting solvents depends on the properties of the organic solvents used as extracting solvents. Factors that should be considered in selecting organic solvent are high extraction efficiency, low volatility, low solubility in water, and the compatibility with direct injection into GC system. ${ }^{1.5}$ Several organic solvents such as trichloroctlylene, tolucte. carbon tetrachloride, and octane were used to investigate the extraction efficiency of nerve agents. The experiments were performed using deionized water solution containing $10 \mu \mathrm{g} / \mathrm{L}$ concentrations of nerve agents for $10 \mathrm{~min}$ at stiming of 200 rpm, and three repetitive extractions were successively conducted for each solvent. As illustrated in Fig. 2, trichloroethylene showed higher extraction efficiency. In addition, negligible solubility of tricloloroetlylene in water $\left(0.1 \%\right.$ at $25^{\mathrm{th}} \mathrm{C}$ ) increased the drop stability. Therefore, trichloroethylene was chosen for subsequent experiments.

Stiming Rate. The effect of stirring rate on the extraction efficiency was investigated between ranges of $0 \mathrm{rpm}$ to the maximum of $800 \mathrm{rpm}$. As shown in Fig. 3, the extraction efficiency of GD, GF gradually increased up to the $400 \mathrm{rpm}$, while there was just a litle increase after the $400 \mathrm{rpm}$. These trends were caused by enhancing contacting chance between organic droplet and analyles in an aqueous solution. The extraction efficiency of $\mathrm{GA}$ and $\mathrm{GB}$ showed only a negligible change with increasing stirring rate. Hence, an optimum allowable stirring rate on the inagnetic stirrer was $400 \mathrm{rpm}$ for various analytes. These trends are also consistent with the theory proposed by Nernst and further developed by Lewis and Whitman. The aqueous phase mass transfer coefficient is defined by ${ }^{\text {12 }}$

$$
\beta_{\mathrm{ax} 1}=D_{\mathrm{at}} / \delta_{\mathrm{ak}}
$$

where $\delta_{\mathrm{Aq}}$ is the thickness of liquid layer, $D_{\mathrm{ap}}$ is the diffusion

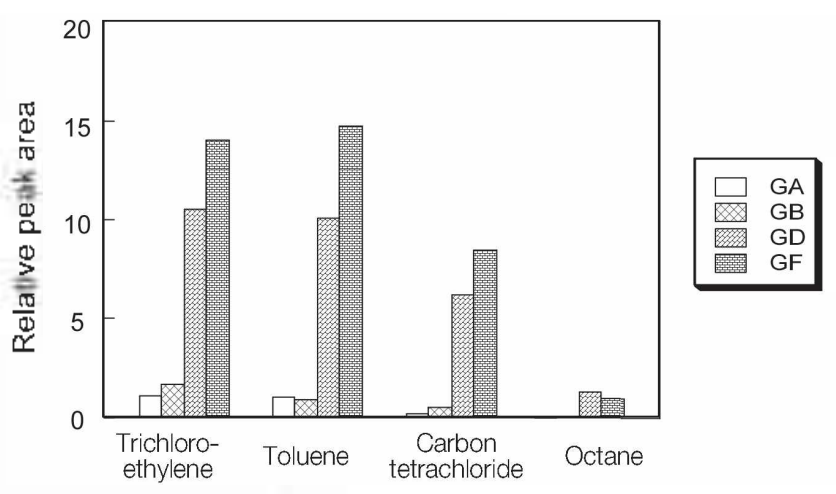

Figure 2. Extraction efficiency of nerve agents with different organic solvents for trichloroethylene, toluene, carbon tetrachloride, and octane. Extraction conditions: concentration, $10 \mu \mathrm{g} / \mathrm{mL}$; extraction time, 10 min. $n^{-3}$ 


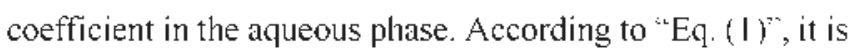
concluded that extraction efficiency increases with increasing stirring rate, because faster stirring makes $\delta_{\text {ill }}$ decrease, so that the value of $\beta_{\text {inl }}$ gets bigger. As a result, we selected the 400 rpm as an optimum stirring rate.

Extraction Iime. To investigate the effect of extraction time, extractions were performed at $10,20,30$, and $40 \mathrm{~min}$. As can be seen in Fig. 4, the amount of extracted $\mathrm{GD}$ and $\mathrm{GF}$ increased with increasing the extraction time up to 30 min. After 30 min, enrichment of GD, GF slightly increased. For $\mathrm{GA}$ and

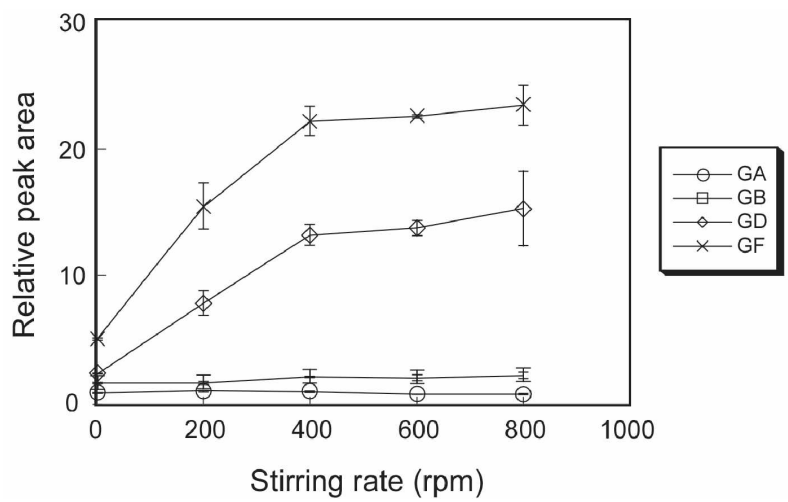

Figure 3. Influence of stirring rate on the extraction efficiency. Extraction conditions: concentration. $10 \mathrm{mg} / \mathrm{mL}$; organic solvent. trichloroethylene; extraction time. $10 \mathrm{~min} . \mathrm{n}=3$

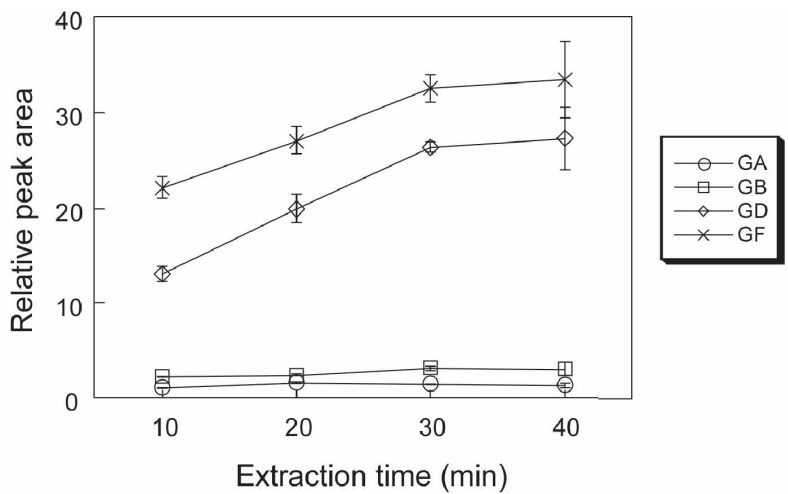

Figure 4. Influence of extraction titme on the extraction efficiency. Extraction conditions: concentration, $10 \mu \mathrm{g} / \mathrm{mL}$; organic solvent trichloroethylene: stirning rate, $400 \mathrm{rpm}$. $\mathrm{n}=3$

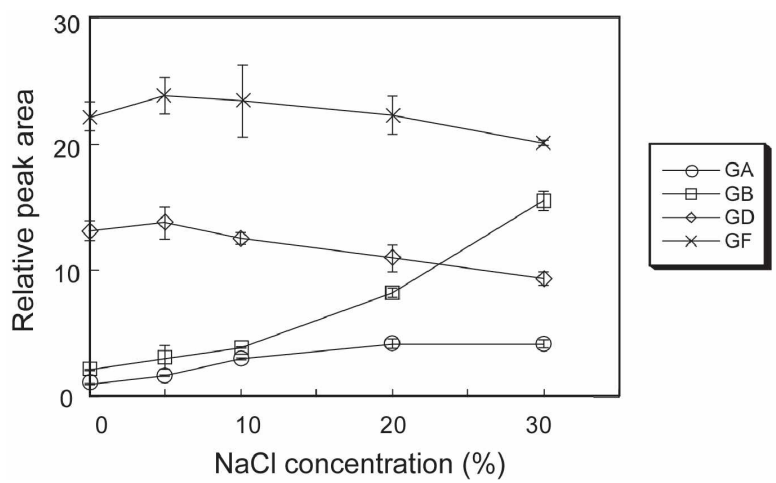

Figure 5. Influence of salt addition on the extraction efficiency. Extraction conditions: concentration, $10 \mu \mathrm{g} / \mathrm{mL}$; organic solvent, trichloroethylene; stirring rate, 400 rpmin: extraction time, 10 min. In 3
GB. enrichment became flat from $10 \mathrm{~min}$. It seems that equilibrium between two phases was established within 10 min. Since dissolution of microdrop was observed after $40 \mathrm{~min}, 30$ min was selected as the optimum extraction time.

Salt Addition. The addition of salt generally increases the extraction efficiency. Since the salt reduces the solubility of analy tes in water, it makes the diffusion of analy tes to organic phase easy (salting out effect). However, there are cases that the extraction efficiency does not change despite the addition of sal1. 15 The reason is generally duc to the physical properties of the Nernst diffusion film by dissolved salt that reduce the rate of diflusion of the analy ies into the drop. ${ }^{1+.15}$ These two effects by the addition of salt were shown in Fig. 5. With the gradual addition up to $30 \%$ of $\mathrm{NaCl}$, the extraction efficiency of $\mathrm{GA}$ and $\mathrm{GB}$ was increased, while extraction efficiency of $\mathrm{G}[$ and $\mathrm{GF}$ was slightly decreased. $20 \% \mathrm{NaCl}$ was selected as optimum condition since extracted amount of $\mathrm{C} A$ was not increased and that of GD and $\mathrm{GF}$ was decreased with $30 \% \mathrm{NaCl}$.

Quantitative Analysis. Under the optimized conditions, repeatability, linearity, and limit of detection (L.ODs) were determined. The trichloroethylene microdrop contained $80 \mu$ $\mathrm{g} / \mathrm{ml}$ of decane as internal standard in order to quantify the nerve agents. As shown in Table I, the linearity was observed in the range of $0.01-1 \mu \mathrm{g} / \mathrm{mL}$ for nerve agents. The correlation coefficicnt $\left(r^{2}\right)$ ranged from 0.9872 to 0.9953 . The L.ODS were $2,2,0.2$, and $0.1 \mathrm{ng} / \mathrm{mL}$ at a signal-to-noise ratio of 3 , and the enrichment factors (ГF) $33.7,8.7,108.7$, and 93.7 were for $\mathrm{GA}, \mathrm{GB}, \mathrm{GD}$, and $\mathrm{GF}$, respectively. The good LODs satisfy the requirement $(1-10 \mu \mathrm{g} / \mathrm{ml})$ of $O{ }^{\top} \mathrm{CW}$ for analy sis of trace $C W / \mathrm{s}$. The assessment of repeatability was investigated in five replicate experiments. The relative standard deviations (RSDs $\%$ ) was from $6.3 \%$ to $9.0 \%$ for nerve agents.

Matrix Effects. To evaluate the feasibility of the SDME melhod for extraction from water sample, sea, river and field water samples were applied. The environmental water samples were extracted using the SIJMt: method in optimized

Table 1. Lincarity, RSDs \% (tr=5), limit of detection (LOD). and enrichment factor (EF) for the SDME of nerve agents fiom deionized water

\begin{tabular}{cccccr}
\hline Compound & $\begin{array}{c}\text { Linear range } \\
(\mu \mathrm{g} / \mathrm{mL})\end{array}$ & $R^{2}$ & $\begin{array}{c}\text { RSDs\% } \\
(\mathrm{n}=5)\end{array}$ & $\begin{array}{c}\text { LOD } \\
(\mathrm{ng} / \mathrm{ml} .)\end{array}$ & \multicolumn{1}{c}{ EF } \\
\hline GA & $0.01-1$ & 0.9872 & 9.0 & 2 & 33.7 \\
GB & $0.01-1$ & 0.9909 & 8.6 & 2 & 8.7 \\
GD & $0.01-1$ & 0.9953 & 7.3 & 0.2 & 108.7 \\
GF & $0.01-1$ & 0.9970 & 6.3 & 0.1 & 9.3 .8 \\
\hline
\end{tabular}

Table 2. Calculated telative recovery (RR) and atrichment factor (Г.F) of nerve agents spike to various water samples. $n=3$

\begin{tabular}{|c|c|c|c|c|c|c|}
\hline \multirow{2}{*}{ Compound } & \multicolumn{2}{|c|}{ Sea water } & \multicolumn{2}{|c|}{ River water } & \multicolumn{2}{|c|}{ Field water } \\
\hline & RR $(\%)$ & FF & RR $(\%)$ & $\Gamma: F$ & RR $(\%)$ & $\Gamma \Gamma$ \\
\hline GA & 84.4 & 28.4 & 74.6 & 25.1 & 87.3 & 29.4 \\
\hline $\mathrm{GB}$ & 56.6 & 4.9 & 93.7 & 8.1 & 78.1 & 6.8 \\
\hline GD & 70.1 & 76.2 & 95.2 & 103.4 & 85.0 & 92.3 \\
\hline $\mathrm{GF}$ & 48.0 & 45.0 & 99.5 & 93.3 & 76.8 & 72.0 \\
\hline
\end{tabular}



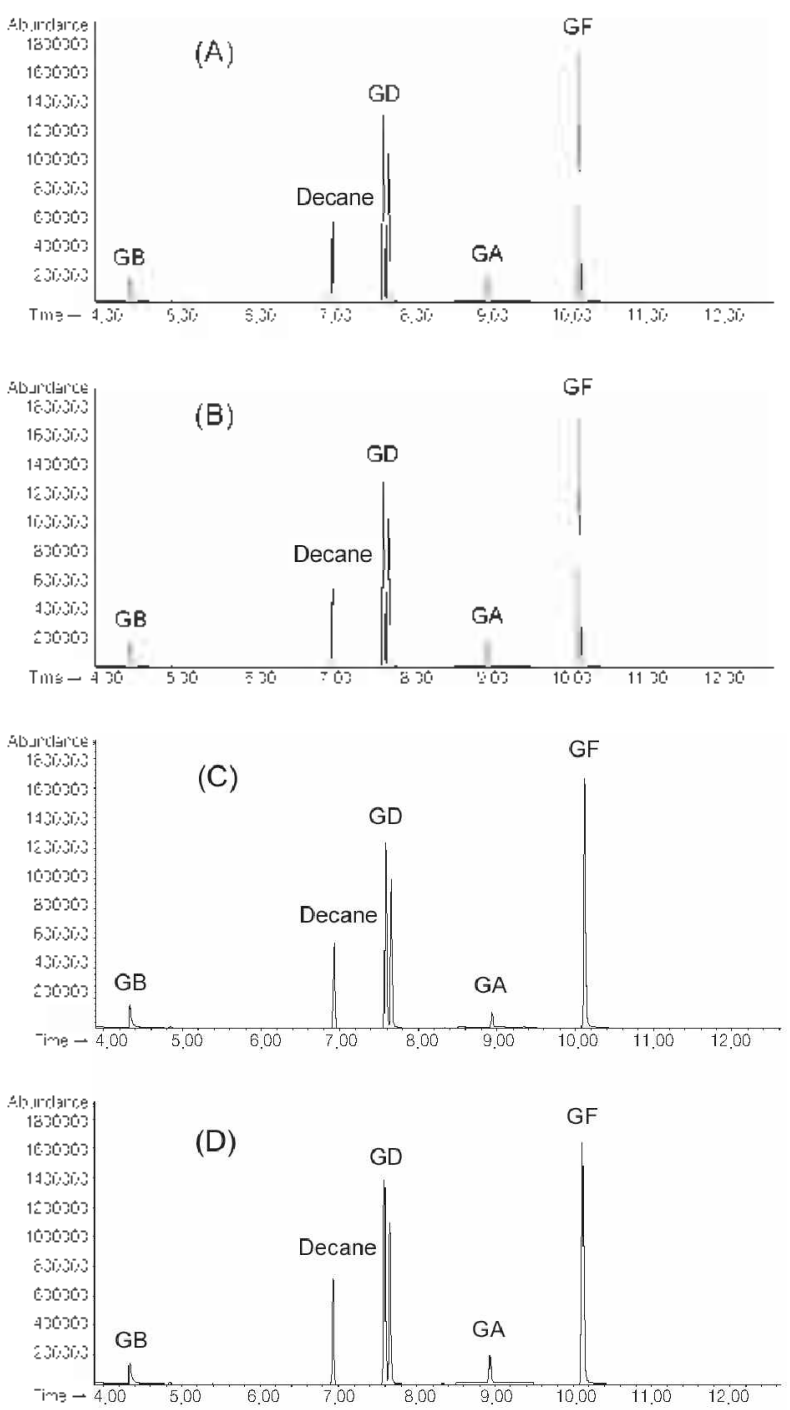

Figure 6. Total ion chromatography of nerve agents in GC-MS analysis obtained by using optinnized conditions. (A) Deionized water sample, (B) sea water sample, (C) river water sample, and (D) field water sample. Extraction conditions: concentration, $1 \mathrm{~kg} / \mathrm{mL}$; organic solvent, trichloroethylene; stiring rate, $400 \mathrm{rpm}$; extraction time, $30 \mathrm{~min}$; salt concentration, $20 \%$.

conditions (organic solvent: trichloroethylene. extraction time: $30 \mathrm{~min}$. stirring rate: $400 \mathrm{rpm}$. salt: $20 \%$ ) and analyzed by GC-MS. All of the water samples were spiked with four nerve agents at $1 \mu \mathrm{g} / \mathrm{mL}$ concentration level to assess the matrix effects. A typical total chromatogram (TIC) of nerve agents obtained by SDME is shown in Fig. 6 . The two peaks of GD of chromatogram are due to its characteristics having two isomers. The resolution and peak shapes after SDME of sea. river. and field water samples are comparable with that of deionized water. The relative recovery is defined as the ratio of the signal intensity of nerve agents spiked in environmental waters to that of the same anount spiked in deonized water. ${ }^{13}$ This value is shown in Table 2 . As we can see. the relative recovery in seawater for four nerve agents was lower than that of river and field water. That is because the cations presented in seawater catalyze degradation of nerve agents ${ }^{4}$ and a basic condition of seawater increase the hydrolysis of nerve agents during the extraction. Also, the enrichment factors (EF, defined as the ration of the peak area obtained after SDME to the peak area obtained with no extraction) were $5(\mathrm{~GB})$ and $76(\mathrm{GD})$ for sea water. $8(\mathrm{~GB})$ and $103(\mathrm{GD})$ for river water. 7(GB) and 92(GD) for field warter. (Table 2) A good recovery and enrichment of analytes proved that this method is versatile for the analysis of nerve agents in environmental samples.

\section{Conclusion}

In the present work, SDME conbined with GC-MS was applied to analyze several kinds of nerve agents (GA. GB. GD. and GF) in water samples. The optinized extraction conditions of solvent selection. extraction time. stirring rate. and salt content were trichloroethylene. $30 \mathrm{~min}$. $400 \mathrm{rpm}$, and $20 \%$. respectively. Also. low LODs $(2 \cdot 0.1 \mathrm{ng} / \mathrm{mL})$ and good repeatability $(6.3 \%-9.0 \%)$ showed the possibility which can be used for the verification of CWAs. And because of not only quick procedure and minimal requirement but also precision and reproducibility, SDME is expected to be useful and suitable method to verify CWAs.

\section{References}

1. Introduction, The Chemical Weapons Convention (CWC), http//wuw.opcw.org/.

2. Pardasani, D.: Palit, M.: Gupta, A. K.; Shakya, P.; Sekhar, K.; Dubey, D. K. Anal. Chem. 2005, 77, 1172.

3. Reddy, T. T.; Saradhil, U. V. R. V.; Prabhahar, S.; Vairamani, M. J. Chomatogr. 12004.1038 .225$.

4. Lakso, H. A.; Ng. W. F. Anal Chem. 1997, 69, 1866.

5. Dubey, D. K.: Pardasani, D.; Gupta, A. K.: Palit, M.; Kanaujia, P. K. Tak, V. J. Chrontatogr, 4 2006, 1107, 29.

6. Lee, H. S. N.; Sng, M. T.; Basheer, C.; Lee, H. K. J. Chromatogr., $12007,1148,8$.

7. Palit, M.: Pardasani, D.; Gupta, A. K.: Dubey, D. K. Anal Chem. 2005, 77, 711.

8. Jung, M. J.; Shin, Y. J.; Oh, S. Y.; Kim, N. S.; Kim, K; Lee, D. S. Bull Korean Chem Soc 2006, 27(2), 231.

9. Shen, G.; Lee, H. K. Anal Chem 2002, 74, 648 .

10. Pardasari D.; Kanaujia, P. K. Gupta, A. K.; Tak, V; Shrivastava, R. K : Dubey, D. K. J. Chrontatogr, $42007,111,151$.

11. Ahmadi, F.: Assadi, Y.: Hosseini, S. M. R. M.: Rezaee, M. J. Chromatogi . 4 2006, 1101, 307 .

12. Teannot, M. A.; Cantwell, F. F. Anal Chem 1997, 69.235.

13. Sekar, R; Wu, H. F. Anal. Chem. 2006, 78, 6306

14. Keith, L. H.; Grummett, W; Deegan, J.; Libbr, R. A.; Taylor, J. K. Wentler, G. Anal Chem, 1983, 55, 2201.

15. Psillakis, E.; Kalogerakis, N. J. Chromatogr, A 2001, 907,211. 